\title{
USO DO DESIGN THINKING NOS PROCESSOS DE INOVAÇÃO EM STARTUPS
}

\author{
Gilberto Perez ${ }^{1}$ \\ Renata Pascon Duarte Lima ${ }^{2}$ \\ Gregory Lee ${ }^{2}$ \\ Caroline Akemi Myai Guiotoko²
}

\footnotetext{
${ }^{1}$ Administração / Centro de Ciências Sociais Aplicadas / Universidade Presbiteriana Mackenzie

${ }^{2}$ CCSA / CCSA / Universidade Presbiteriana Mackenzie
} 


\section{USO DO DESIGN THINKING NOS PROCESSOS DE INOVAÇÃO EM STARTUPS}

Resumo: Com esta pesquisa avaliaram-se aspectos do uso do Design Thinking no processo de inovação em startups. A amostra estudada foi composta por quatro startups localizadas na incubadora de uma importante Universidade do estado de São Paulo. Utilizou-se o método qualitativo e a coleta de dados ocorreu com entrevistas, mediante roteiro previamente elaborado. Os dados coletados foram tratados com a Análise de Conteúdo. Identificaram-se cinco categorias que ilustram o uso do Design Thinking: Processo de Inovação da Startup; Processo de Pesquisa de Mercado; Conceito de Design Thinking da Startup; Prototipação e Pivotação e Resultados Obtidos na Combinação da Inovação e Design Thinking. Os resultados indicam que o Design Thinking é utilizado pelas startups de forma intuitiva, e pode-se dizer que não existe, por parte das startups estudadas, um conhecimento teórico sobre o tema. Por fim, evidencia-se o impacto positivo no processo de inovação das startups tanto em produtos como em processos.

Palavras-chave: Design Thinking. Startup. Inovação. Prototipação.

\section{Introdução}

Segundo Porter (1989), não é desejável competir por preço, a organização deve buscar pela diferenciação ou ir de encontro a segmentos cada vez mais específicos, para alcançar a vantagem competitiva. Apesar desta afirmação ter sido escrita a vários anos atrás, ela se faz atual, já que cada vez mais é percebida a necessidade de diferenciação para as empresas terem destaque no mercado, com o crescimento da tecnologia e do envolvimento dos consumidores na vida das empresas essa tarefa não tem sido fácil.

Desta forma, o tema inovação vem se tornando bastante pesquisado e estudado. Schumpeter (1982) defende que a inovação é fundamental para o crescimento econômico e é um meio para se alcançar a diferenciação; Brown (2008) também reflete sobre a ideia da inovação como importante fonte para a vantagem competitiva. Embora o tema inovação ser citado como atual ele já vem sendo estudado há anos, porém novas abordagens estão surgindo conforme o assunto é aprofundado, assim como novos pesquisadores.

Design Thinking é uma abordagem para a inovação, que se vale de técnicas usadas pelos designers de forma adaptada, com o objetivo de resolver problemas. O Design Thinking é baseado em observações e contato direto com os stakeholders, sendo eles desde clientes e potenciais clientes até os próprios profissionais envolvidos no processo, sendo assim uma abordagem colaborativa e experimental.

O termo startup está ligado ao ato de começar/criar algo, geralmente relacionado a empresas jovens e empreendedoras, que buscam a inovação como principal meio para alcançar o objetivo de colocar sua ideia e sua organização em funcionamento. São pequenas empresas que vivem em cenário de incerteza, e apesar de ter forte influência no setor tecnológico e computacional, envolve diversas áreas e possibilidades.

Esta pesquisa apresenta diferentes seções, em que os temas anteriores serão abordados, além da introdução também conceitua o Design Thinking e Startup, relaciona o Design Thinking

\section{Organizadores:}

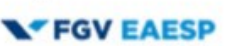

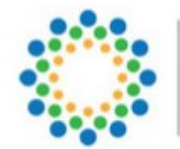

ANEGEPE

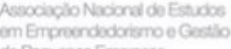
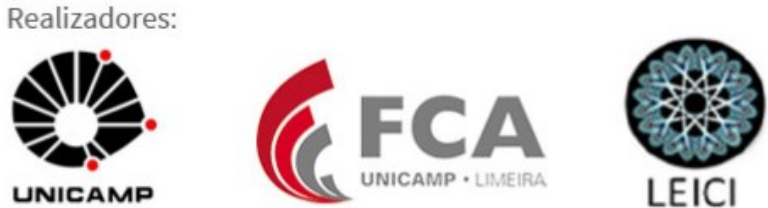
com inovação e apresenta o papel da inovação nas startups estudadas, buscando identificar resultados obtidos. Posteriormente apresentam-se as análises, conforme procedimentos metodológicos e considerações finais da pesquisa. A questão de pesquisa que se procurou responder ficou assim enunciada: Como as startups utilizam o Design Thinking no seu processo de inovação?

O objetivo geral do trabalho foi: Investigar a utilização da abordagem do Design Thinking no processo de inovação de startups. Para responder à questão de pesquisa e atingir o objetivo geral, elaboram-se três objetivos específicos: 1) Identificar como ocorre a utilização do Design Thinking em startups; 2) Verificar as vantagens e desvantagens na utilização do Design Thinking em startups e 3) Investigar resultados obtidos por startups ao praticarem tal abordagem.

Partindo da contemporaneidade dos assuntos abordados, assim como o crescente surgimento de startups e principalmente o aumento dos estudos relacionados ao Design Thinking o grupo pretendeu entender o quanto esse novo tema vem influenciando a inovação nas startups.

\section{Referencial Teórico}

Neste capítulo são apresentadas as teorias que deram suporte aos construtos bases da pesquisa: Inovação e Startups e Design Thinking.

\subsection{Inovação: Conceitos, Tipos e Graduação}

O conceito de inovação é muito confundido com o conceito de invenção. Segundo Zawislak (2008) inovação é uma combinação nova de conhecimentos que gera um valor e não só uso. Já a invenção, ainda segundo Zawislak (2008) é uma nova solução viável para um problema. A invenção fica restrita a ideias e esboços, e a inovação é a solução de fato do problema.

Segundo Tidd, Bessant e Pavitt (2015), inovação não é só a abertura de novos mercados, mas também novas formas de servir a mercados maduros. A mesma é movida pela percepção da oportunidade e tirar proveito sobre. Segundo Manual de Oslo (OCDE, 1997, p.55), inovação é a implementação de um bem ou serviço novo ou melhorado. No Quadro 1, apresenta-se uma síntese dos conceitos apresentados pelos autores pesquisados.

Quadro 1: Conceitos de Inovação.

\begin{tabular}{|l|l|}
\hline \multicolumn{2}{|c|}{ INOVAÇÃO } \\
\hline \multicolumn{1}{|c|}{ Autores } & \multicolumn{1}{c|}{ Conceitos } \\
\hline OCDE (1997) & Inovação é a implementação de um bem ou serviço novo, ou melhorado. \\
\hline $\begin{array}{l}\text { Tidd, Bessant e Pavitt } \\
(2015)\end{array}$ & $\begin{array}{l}\text { Inovação é a abertura de novos mercados, ou também uma nova forma de servir os } \\
\text { mercados maduros. É movida pela oportunidade. }\end{array}$ \\
\hline
\end{tabular}

Fonte: Tidd, Bessant e Pavitt (2015); OCDE (1997). 
Segundo Manual de Oslo (OCDE, 1997), uma empresa pode realizar vários tipos de mudanças e assim aumentar a produtividade. Definindo assim dois tipos de inovação que foram evidenciados na pesquisa e será apresentado nos próximos tópicos.

Segundo Manual de Oslo (OCDE, 1997), o termo "produto" se diz respeito a bens ou serviços, essa inovação caracterizada então a introdução de um produto novo ou melhorado no qual atinge suas características previstas. No âmbito de serviços a inovação pode ser adição de novas funções em serviços já existentes ou um serviço completamente novo. Ainda no Manual de Oslo (OCDE, 1997), são citados exemplos de inovação de produto, um deles é o uso de tecidos respiráveis em vestuários, onde são utilizados novos materiais para produção; e para inovação de serviço um exemplo interessante é a melhora nos serviços bancários via internet.

Para Osterwalder, Pigneur e Clark (2011), inovação dos modelos de negócios é uma valorização não só para a empresa, mas para os clientes e também para toda sociedade, essa inovação surge com a necessidade emergentes dos usuários. É citado como exemplo o Skype, que criou um novo modelo de negócio na tecnologia para realização de ligações internacionais gratuitas. Apresenta-se no Quadro 2, os tipos de inovação encontrados na literatura pesquisada.

Quadro 2: Tipos de Inovação Pesquisadas.

\begin{tabular}{|c|c|}
\hline \multicolumn{2}{|r|}{ TIPOS DE INOVAÇÃO } \\
\hline Autores & Conceitos \\
\hline \multicolumn{2}{|r|}{ Inovação de Produto } \\
\hline OCDE (1997) & $\begin{array}{l}\text { Implementação de um bem ou serviço novo ou melhorado, que atende sua } \\
\text { característica prevista. }\end{array}$ \\
\hline \multicolumn{2}{|r|}{ Inovação de Modelo de Negócio } \\
\hline $\begin{array}{l}\text { Osterwalder, Pigneur e Clark } \\
\text { (2011) }\end{array}$ & Uma valorização que surge das necessidades dos clientes. \\
\hline
\end{tabular}

Fonte: OCDE (1997); Osterwalder, Pigneur e Clark (2011).

Para Tidd, Bessant e Pavitt (2015) existem diferentes graus de novidades, desde a incremental que são as menores, até as radicais que transformam o modo de ver e usar as coisas. A Incremental, segundo os autores, se refere a melhoramentos contínuos, é a mais comum em países em desenvolvimento. Já a Radical, segundo Manual de Oslo (OCDE, 1997) é caracterizada pelo desenvolvimento de um novo produto ou serviço, e é mais significativa do que Incremental

Certamente existem outros conceitos, tipos (ou classes) e graus de inovação apresentados por outros autores. Não foi intenção desta pesquisa, exaurir esses conceitos, mas sim, ilustrar com eles, algumas características peculiares inerentes à inovação. Para fins da pesquisa, é importante destacar que, nenhum desses conceitos foi considerado como sendo o mais relevante para o seu desenvolvimento.

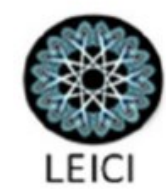




\subsection{Startups e Empreendedorismo}

Para conceituar startup é necessário conhecer as definições/conceitos de empreendedorismo e inovação. Diversas transformações vêm ocorrendo no mundo e cada vez em menores períodos, em sua maioria referem-se a invenções decorrente de diversas tipologias de inovação, e por trás destas existem pessoas e equipes com características determinísticas e especiais. Através desta visão da economia, Dornelas (2016) define empreendedores como pessoas diferenciadas, com determinação, motivadas e apaixonadas que procuram reconhecimento e querem deixar seu legado. Ainda para Dornelas (2016), empreendedorismo é definido pela junção de pessoas e processos que levam ideias a se transformarem em oportunidades.

Dolabela (2006) define empreendedor como alguém que sonha e busca transformar seu sonho em realidade, sendo um ser social e produto do meio em que está inserido. Para Dolabela (2006) o empreendedorismo existe desde sempre, a começar da primeira ação humana inovadora, com o objetivo de melhorar as relações do homem seja com os outros seja com a natureza, e é definido por iniciativa e inovação, não considerando empreendedorismo a aquisição de uma organização sem a aplicação de algum tipo de ação inovadora.

De acordo com Schumpeter (1982) o empreendedorismo está na percepção e no aproveitamento de novas oportunidades, criando uma nova combinação de recursos que o empreendedor já esteja familiarizado. Para compreender o foco cada vez maior dos países em atividades empreendedoras, Dornelas (2016) traz como exemplo os Estados Unidos, que com intensos e constantes investimento em empreendedorismo, tanto por parte do governo como por meio de organizações privadas, mesmo em situações de crise, e a crença de que o empreendedorismo é e continuará sendo o grande propulsor da economia américa, faz com que o país seja modelo para outros países que desejam aumentar suas atividades empresariais.

Dolabela (2006) retrata o empreendedor como combustível para o crescimento da economia e para o desenvolvimento social, tratando o conceito não somente como indivíduos, mas de comunidades, regiões e países, implicando ideia de sustentabilidade. O conceito de empreendedorismo vem sendo discutido com maior ênfase no Brasil a partir do final da década de 1990, ganhando força nos anos 2000, conquistando forte participação nos estudos acadêmicos e nos programas de incentivo do governo, e até mesmo de empresas e órgãos privados (DORNELAS, 2016).

\subsubsection{Startup: Conceitos}

De acordo com Ries (2012), startup é uma instituição humana desenhada para criar um novo produto ou serviço de maneira inovadora em condições de extrema incerteza, o próprio autor percebe que o mais importante nesta definição está omitido, ele refere-se ao porte, segmento ou setor da economia que a empresa faça parte. Tal omissão demonstra que independente das variáveis citadas, qualquer pessoa que esteja criando em condições de incerteza está empreendendo.

O termo "extrema" é questionado por Hartmann (2013), que confirma a presença da incerteza, mas não de forma extrema, trazendo a sua definição de startup como uma organização com o objetivo de criação de solução para um grupo de pessoas. Relacionando

Organizadores:

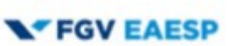

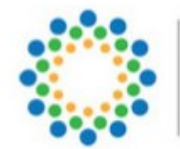

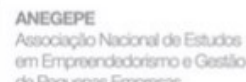

Realizadores:
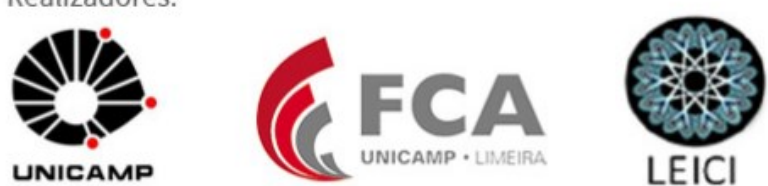
empresas tradicionais e startups Hartmann (2013) diz que a grande diferença entre elas está na fase inicial; enquanto as tradicionais costumam planejar e utilizar planos de negócios, projetos de viabilidade e posteriormente a execução, as startups têm maior conexão com o mercado nesta fase usando métodos de tentativa e erro.

Segundo Alves (2013) startup reflete empresas em estágio inicial que investem em inovação, seja em produtos ou serviços. Neste período as empresas entram em experimentação testando suas hipóteses, obtendo sucesso ou insucesso. No caso de sucesso a startup entra em crescimento, passando pela transição e transformando-se em uma empresa tradicional; do contrário a startup acaba deixando de existir.

Com mudanças nos paradigmas produtivos e estratégias de negócios, a inovação se torna elemento fundamental para o alcance da vantagem competitiva, e as startups representam muito bem esse novo cenário dado que sua característica mais forte é inovação (ALVES, 2013). A inovação nas startups é representada pelos produtos ou serviços, totalmente ou parcialmente, novos no contexto em que está inserido, desenvolvendo aprendizado e conhecimento, habilidades muito importantes para o alcance da competitividade no cenário econômico atual (ALVES, 2013).

Nos conceitos expostos no subtópico anterior e nos parágrafos acima, fica visível que inovação é uma característica essencial das startups. Ries (2012) justifica esta relevância através da evidência de que o produto ou serviço entregue por startup ser resultante da inovação; gerando um novo valor ao cliente, independente de qual dos diversos tipos de inovação, esteja sendo empregada ela é o ponto chave para o sucesso de uma startup.

\subsection{Design Thinking}

Conforme Brown (2010), Design Thinking é um método que se baseia nos sentidos e raciocínios de um designer, ou seja, pensar como um designer, para assim alterar a maneira de desenvolver produtos, serviços e processos, atendendo as necessidades das pessoas com uma tecnologia mais viável, tendo como objetivo criar uma estratégia duradoura, agregando valor para o cliente e oportunidade de mercado. Para Brown (2010), o Design Thinking tem como objetivo criar novas experiências, valores e significado para os consumidores por meio do desenvolvimento de soluções e ideias com novas aplicabilidades.

Para Bonini e Endo (2010, p.6), o Design Thinking "possui uma visão otimista, construtiva e experimental" pois ao utilizar a forma como um designer pensa, é feito um levantamento das questões-chave do problema, estimulando a criação de hipóteses e utilização do seu conhecimento, para se chegar no desenvolvimento de soluções específicas e mais eficazes.

Segundo Signori et al. (2014), o Design Thinking tem como objetivo a busca contínua por soluções específicas, e atender as necessidades do usuário, utilizando o pensamento abdutivo, onde por meio da elaboração de hipóteses e utilização do conhecimento existente, favorece o desenvolvimento de soluções mais eficientes.

De acordo com Vianna et al. (2012), o Design Thinking também surge através do modo como um designer pensa, e também utiliza o pensamento abdutivo, onde são elaborados questionamentos a serem respondidos por meio das observações realizadas que envolvem o problema, e a partir delas tomar medidas de soluções. Ou seja, a solução não é derivada do
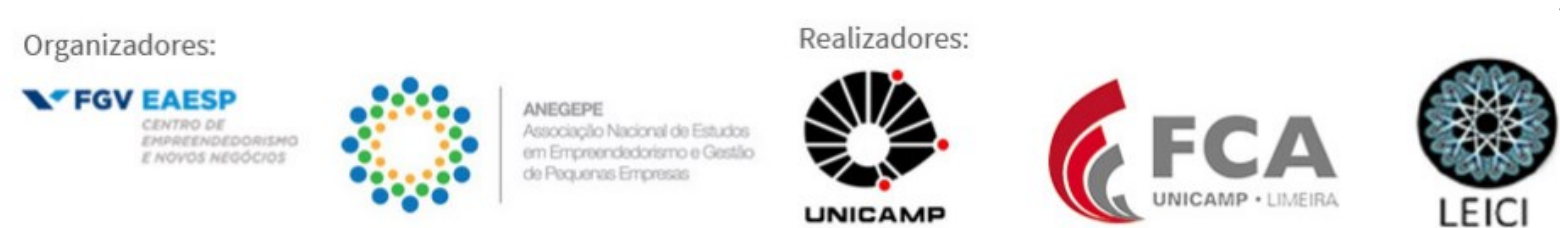
problema, mas sim dos fenômenos que estão em torno dela. Utilizando o pensamento abdutivo, o designer consegue se desprender do pensamento lógico cartesiano e dessa forma desafiar constantemente seus padrões e criar novas oportunidades de inovação (VIANNA et al., 2012).

Para MJV (2016) Design Thinking traz uma visão integrada da inovação, sendo formada por profissionais multidisciplinares, possibilitando a análise das partes interessadas para gerar soluções. Argumenta também que além de tecnologia e ciência, o Design Thinking utiliza de elementos lúdicos para abordar os mais complexos problemas de negócio e gerar inovação. O Quadro 3 apresenta uma síntese dos conceitos pesquisados de Design Thinking.

Quadro 3: Conceitos de Design Thinking.

\begin{tabular}{|c|c|}
\hline \multicolumn{2}{|r|}{ DESIGN THINKING } \\
\hline Autores & Conceitos \\
\hline Brown (2010) & $\begin{array}{l}\text { Design Thinking é um método que se baseia nos sentidos e raciocínios de um } \\
\text { designer para alterar a maneira de desenvolver produtos, serviços e processos } \\
\text { atendendo as necessidades das pessoas, com uma tecnologia mais viável. }\end{array}$ \\
\hline Bonini e Endo (2010) & $\begin{array}{l}\text { Design Thinking possui uma visão otimista, construtiva e experimental, } \\
\text { utilizando a forma como um designer pensa e estimulando a criação de hipóteses } \\
\text { e a utilização do seu conhecimento para chegar no desenvolvimento de soluções } \\
\text { específicas e mais eficazes. }\end{array}$ \\
\hline Vianna et al. (2012) & $\begin{array}{l}\text { Design Thinking surge através do modo como um designer pensa, e utiliza o } \\
\text { pensamento abdutivo, onde são elaborados questionamentos a serem } \\
\text { respondidos, por meio das observações realizadas que envolvem o problema, e a } \\
\text { partir delas tomar medidas de soluções. }\end{array}$ \\
\hline Signori et al. (2014) & $\begin{array}{l}\text { Design Thinking tem como objetivo a busca contínua por soluções específicas e } \\
\text { o de atender as necessidades do usuário, utilizando o pensamento abdutivo, onde } \\
\text { por meio da elaboração de hipóteses e utilização do conhecimento existente, } \\
\text { favorece o desenvolvimento de soluções mais eficientes. }\end{array}$ \\
\hline MJV (2016) & $\begin{array}{l}\text { Design Thinking traz uma visão integrada da inovação, sendo formada por } \\
\text { profissionais multidisciplinares. }\end{array}$ \\
\hline
\end{tabular}

Fonte: Brown (2010); Bonini e Endo (2010); Vianna et al. (2012); Signori et al. (2014); MJV (2016).

\subsubsection{Etapas do Design Thinking}

Para Brown (2010), o processo de Design Thinking é fundamentado em três etapas: inspiração, idealização e implementação. Durante essas etapas, os problemas são levantados, ideias são elaboradas e testadas e por último as respostas são obtidas.

Segundo MJV (2016) o Design Thinking é dividido em cinco etapas que serão seguidas pelos funcionários como estratégia, sendo elas: Imersão, Análise, Ideação, Prototipagem e Implementação.

Para Vianna et al. (2012) as etapas são divididas também em três etapas com os mesmos conceitos citados por Brown (2010), porém ele as trata como: Imersão, Ideação e Prototipação, conforme indicado na Figura 1. Ainda de acordo com o autor, o processo de Design Thinking pode começar por qualquer uma das etapas citadas, conforme sua natureza e tipologia, sendo assim versátil e não linear.
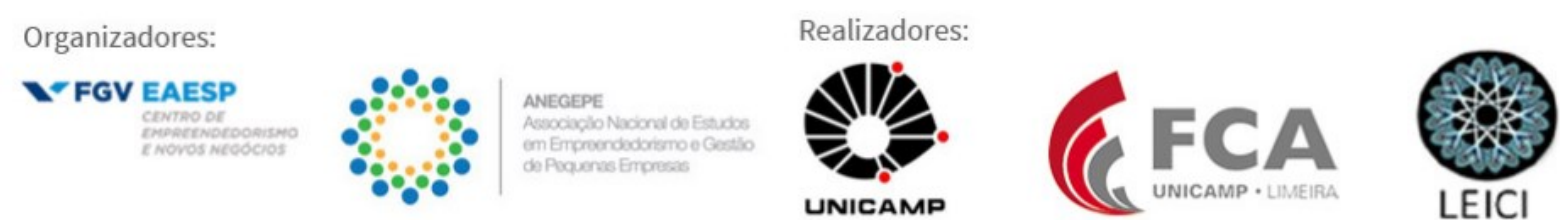
Desta forma, neste estudo optou-se por utilizar os conceitos conforme Vianna et al. (2012) e Brown (2010), porém como utilizam denominações diferentes, o grupo irá usar a nomenclatura de Vianna et al. (2012).

Figura 1 - Esquema representativo das etapas do processo de Design Thinking.

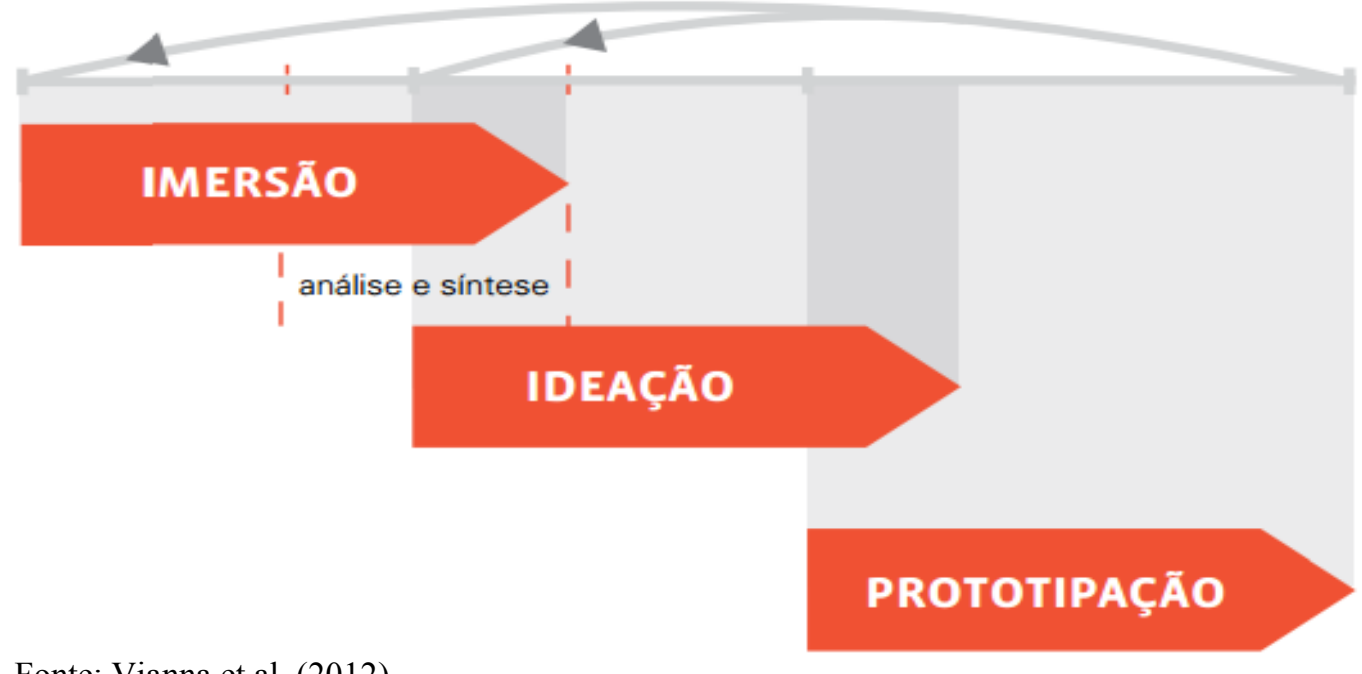

Fonte: Vianna et al. (2012).

A primeira etapa do processo de Design Thinking chama-se Imersão. "Nesse momento a equipe de projeto aproxima-se do contexto do problema, tanto do ponto de vista da empresa quanto do usuário final" (VIANNA et al., 2012, p.21). Nessa parte do processo, ela é dividida em duas etapas: Imersão Preliminar e Imersão em Profundidade (VIANNA et al., 2012).

Segundo Vianna et al. (2012), na imersão preliminar, geralmente a equipe de projeto não conhece o problema, então é definido o escopo do projeto e as suas fronteiras, passando assim a ter um entendimento e aproximação maior com o problema.

Após a compreensão do problema, Vianna et al. (2012) descreve que a próxima etapa consiste no aprofundamento do tema, por meio da imersão em profundidade, onde são conhecidos os perfis de usuários, tendo como foco o ser humano, com objetivo de identificar seus anseios, necessidades e valores. Para isso o autor diz ser necessário levantar informações de quatro tipos: "O que as pessoas falam? Como agem? O que pensam? Como se sentem?".

Ao fim da etapa de Imersão, os dados obtidos das pesquisas preliminares e em profundidades são analisados, cruzando as informações a fim de identificar padrões e oportunidades (insights) que serão utilizadas na geração de soluções (VIANNA et al., 2012).

De acordo com Brown (2010) esta primeira etapa tem como objetivo a aproximação e entendimento do contexto do problema, identificando as necessidades e oportunidades dos usuários finais por meio da empatia, e colocando-se no papel do usuário, além do pensamento abdutivo, sendo assim elaboradas questões que serão respondidas através dos dados e informações coletadas durante a observação.

A segunda etapa é a Ideação que, Para Brown (2010), é a etapa onde são trabalhados os problemas identificados na etapa de imersão, no qual as ideias e conceitos são gerados e prototipados, com o objetivo de gerar inovações. Segundo Vianna et al. (2012) essa fase do

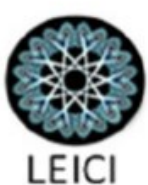


projeto consiste na elaboração de ideias inovadoras, por meio de ferramentas que estimulam a criatividade e geram soluções para o problema abordado.

De acordo com Brown (2010) a fase de ideação geralmente inicia-se com o brainstorming, que é uma técnica em grupo que por meio de regras estruturadas, como não criticar a ideia do outro, incentivar o desenvolvimento de novas ideias, manter-se concentrado no assunto, e principalmente tomar como base a ideia dos outros, faz com que todos os participantes se envolvam de forma interativa, resultando nas melhores ideias.

Após a criação de diversas ideais, é feita uma ou mais sessões de co-criação com as partes envolvidas, onde estas são melhores trabalhadas, diferentes especialistas se fazem necessários (VIANNA et al., 2012). As ideias geradas ao longo desse processo segundo Vianna et al. (2012) são validadas pela ferramenta Matriz de Posicionamento, que tem como finalidade selecionar as ideias mais eficientes e que melhor correspondam aos desafios de cada solução, ou seja, com potencial mais elevado, para serem prototipadas.

Para Brown (2010) na etapa de ideação para uma ideia ser prototipada, é necessário selecionar as melhores ideias e converter em algo tangível, saindo da geração para sua resolução.

A terceira e última etapa é a Prototipação. Para Bonini e Endo (2010, p.4), "O Design Thinking trabalha intensamente a criação de oportunidades, ou melhor, hipóteses, que são resultado de sessões de criatividade que criam e reciclam o conhecimento gerado pela prototipagem". Além disso, conforme Bonini e Endo (2010), diferentemente dos modelos tradicionais, onde o principal resultado é a minimização de riscos e levantamento do potencial de lucratividade, este visa aprender pelos pontos fortes e fracos da ideia, além da identificação de novos rumos para esse protótipo.

Segundo Vianna et al. (2012), os protótipos auxiliam na identificação de solução mais assertiva, já que descartam alternativas indevidas, reduzindo dessa forma as incertezas do projeto. Ainda de acordo com Vianna et al. (2012, p.125), "Prototipações, portanto, nada mais são que simulações que antecipam problemas, testam hipóteses e exemplificam ideias de modo a trazê-las à realidade para abrir discussões". Dessa forma, para obter maior chances de aprendizado e sucesso da solução, deve-se começar o quanto antes e realizar o maior número de testes possíveis (VIANNA et al., 2012).

Conforme Signori et al. (2014), esta metodologia por apresentar uma rápida prototipagem e transformar uma ideia em algo mais tangível, gera maiores chances de resultados inovadores, uma vez que os consumidores estão envolvidos em todas as etapas do processo, testando e autenticando em cada etapa, pela busca das melhores soluções para o abordado problema.

\subsection{Design Thinking x Inovação}

Para Macedo, Miguel e Casarotto Filho (2015) o Design Thinking está ligado a inovação através do conceito de inserção de algo novo no mercado, através da observação do consumidor visando a solução de um problema específico com foco no usuário, criando valor ao cliente e consequentemente para a organização. Ainda segundo Macedo, Miguel e Casarotto Filho (2015) o Design Thinking apresenta, através das fases que o compõem, a possibilidade de compreender quais os recursos e habilidades são necessárias para o desenvolvimento de uma
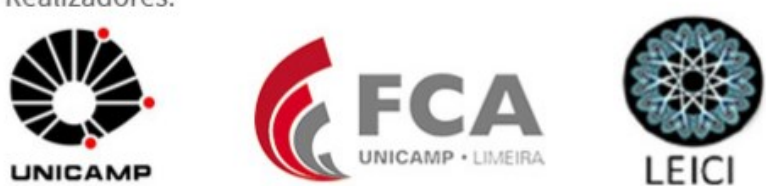
inovação, mostrando em suas atividades características que a define como um modelo de inovação. Apresentando também fatores importantes e essenciais para o processo de inovação dentro de organizações em diversas áreas e grau de inovação.

De acordo com Signori et al. (2014) o Design Thinking se apresenta como uma influente ferramenta, com um novo enfoque, contemplando todo o processo de inovação, desde a visualização de insight e potenciais oportunidades até a filtragem e geração de ideias nesses insights, e no desenvolvimento através da prototipagem. Os mesmos autores descrevem o Design Thinking como uma metodologia com visão otimista, construtiva e experimental, com foco em na resolução das necessidades do cliente, seja em produtos ou serviços. Varrichio (2016) aponta um maior interesse das grandes empresas na aproximação com empresas startups, sendo encaradas como uma fonte de inspiração, conhecimento e inovação tecnológica.

\section{Procedimentos Metodológicos}

Segundo Richardson (2008), o método qualitativo não pretende numerar ou medir os resultados, e sim analisar interação de variáveis, classificar processos dinâmicos vividos por grupos, em suma, estudos de comportamentos de indivíduos. Esse método explora a observação e entrevistas, tanto para coleta de dados, como para análise do conteúdo. Desta forma utilizouse o método qualitativo visando analisar o comportamento das startups em relação ao uso do Design Thinking.

Optou-se pela pesquisa exploratória para o estudo, já que o tema proposto não possui muitas pesquisas realizadas (GIL, 2008) e está sendo baseado na utilização do Design Thinking em startups. A partir de tal tipo de pesquisa, pretendeu-se explorar o tema no âmbito das startups de modo a atingir os objetivos estabelecidos e agregar conteúdo para futuros estudos.

Devido à natureza do estudo optou-se pela entrevista como instrumento de coleta de dados, estabelecendo uma conexão com as pessoas responsáveis pela inovação nas startups, procurando entender o processo de inovação ao qual está inserida e identificar a utilização, características e resultados do Design Thinking. Para realização das entrevistas utilizou-se um roteiro de entrevistas previamente elaborado.

A partir da utilização do método qualitativo empregou-se a técnica da análise de conteúdo. Richardson (2008) e Bardin (2011) defendem que esta análise é particularmente utilizada para materiais qualitativos pela não aplicação de técnicas aritméticas, dessa forma é necessário fazer a leitura do conteúdo para organizar as ideias e posteriormente analisar aquilo que as determinam. Devendo ser eficaz, rigorosa e precisa, para que os momentos mais importantes sejam extraídos e compreendidos de forma a possibilitar sua repetição por outros autores. Ainda segundo os autores, toda comunicação que envolve um emissor e um receptor pode ser um objeto de análise de conteúdo.

Para a realização do estudo entrevistaram-se funcionários e/ou colaboradores da área de inovação atuantes em uma Incubadora de Empresas de uma importante Universidade localizada na cidade de São Paulo, que por questões de sigilo tiveram sua identidade preservada. 


\section{Apresentação e Análise dos Resultados}

Ao todo foram realizadas quatro entrevistas, mediante um roteiro previamente elaborado, com os proprietários das startups estudadas na Incubadora da Universidade localizada em São Paulo, no segundo semestre de 2017.

\subsection{Perfil dos Entrevistados}

No Quadro 4 apresenta-se o perfil dos entrevistados das quatro entrevistas realizadas. A identidade das empresas e dos entrevistados foram preservados, por questões de sigilo garantido.

Quadro 4: Perfil dos Entrevistados.

\begin{tabular}{|c|c|c|c|c|}
\hline \multicolumn{5}{|c|}{ PERFIS DOS ENTREVISTADOS } \\
\hline & E1 & E2 & E3 & $\mathbf{E 4}$ \\
\hline $\begin{array}{l}\text { Data da } \\
\text { Entrevista }\end{array}$ & 05/09/2017 & $02 / 10 / 2017$ & 03/10/2017 & $04 / 10 / 2017$ \\
\hline $\begin{array}{l}\text { Entrevistado/a } \\
\text { (s) - Iniciais }\end{array}$ & $\begin{array}{l}\text { C. G. } \\
\text { Y.F. }\end{array}$ & F. S. & M. M. & B. S. \\
\hline Cargo & $\begin{array}{l}\text { Co-Fundador } \\
\text { Co-Fundador }\end{array}$ & Fundador/Sócio & $\begin{array}{c}\text { Fundadora/Sócia/ } \\
\text { Estilista }\end{array}$ & CEO-Fundador \\
\hline $\begin{array}{l}\text { Formação } \\
\text { Profissional }\end{array}$ & $\begin{array}{l}\text { Urbanista- } \\
\text { Paisagista } \\
\text { Urbanista }\end{array}$ & $\begin{array}{l}\text { Engenharia de } \\
\text { Produção }\end{array}$ & $\begin{array}{c}\text { Ciências } \\
\text { Contábeis e } \\
\text { Design de Moda }\end{array}$ & $\begin{array}{l}\text { Administração de } \\
\text { Empresas }\end{array}$ \\
\hline $\begin{array}{l}\text { Tempo na } \\
\text { Organização }\end{array}$ & $\begin{array}{c}\text { Desde Maio de } \\
2017\end{array}$ & Desde 2016 & Desde 2014 & Desde 2016 \\
\hline
\end{tabular}

Fonte: Autores (2017).

\subsection{Análise de Conteúdo}

Utilizando-se entrevistas realizadas coletaram-se informações das startups pesquisadas. As entrevistas foram gravadas e posteriormente transcritas. Com base na análise de conteúdo destacaram-se as principais ideias e conteúdos obtidos durante as entrevistas. A partir desses conteúdos foram adotadas três etapas para evidenciar tais pontos e auxiliar na análise dos dados.

Na primeira etapa foram identificados pontos de destaque (Unidades de Registro - UR) em cada uma das perguntas feitas aos entrevistados. Na segunda etapa criaram-se as 12 Unidades de Significado (US) definidas pelo agrupamento de URs similares. Por fim, na terceira etapa, formaram-se cinco Categorias (C), que estão ligadas aos objetivos do estudo (Quadro 5), e que estão descritas a seguir. 
Quadro 5: Categorias Identificadas.

\begin{tabular}{|l|l|}
\hline \multicolumn{1}{|c|}{ CATEGORIAS } & \multicolumn{1}{c|}{ UNIDADE SIGNIFICADO } \\
\hline C1 - Processo de Inovação da Startup & $\begin{array}{l}\text { US.1 - Conceito de Inovação } \\
\text { US.11 - Impactos no Processo de Inovação } \\
\text { US.12 - Características da Inovação }\end{array}$ \\
\hline C2 - Processo de Pesquisa de Mercado & $\begin{array}{l}\text { US.3 - Tipo e objetivo da Pesquisa de Mercado } \\
\text { US.5 - Análise de Resultados } \\
\text { US.6 - Processo de Seleção de Ideias }\end{array}$ \\
\hline \multirow{2}{*}{ C3 - Conceito de Design Thinking da Startup } & $\begin{array}{l}\text { US.2 - Entendimento do Design Thinking, suas Vantagens e } \\
\text { Desvantagens } \\
\text { US.8 - Utilização de Equipes Multidisciplinares }\end{array}$ \\
\hline C4 - Prototipação e Pivotação & $\begin{array}{l}\text { US.4 - Decisão de Pivotar } \\
\text { US.7 - Processo de Prototipação }\end{array}$ \\
\hline $\begin{array}{l}\text { C5 - Resultados Obtidos na Combinação da } \\
\text { Inovação e Design Thinking }\end{array}$ & $\begin{array}{l}\text { U.S.9 - Surgimento de Produtos e Serviços } \\
\text { U.S.10 - Ganho de Clientes }\end{array}$ \\
\hline
\end{tabular}

Fonte: Autores (2017).

A categoria C1: Processo de Inovação da Startup relaciona a inovação com OCDE (1997), que conceitua inovação como a implementação de um bem ou serviço novo, ou melhorado. Também com o conceito de Tidd, Bessant e Pavitt (2015) que conceituam a inovação com a abertura de novos mercados, ou também uma nova forma de servir os mercados maduros.

E2: É a aplicação de um serviço novo que não existe ainda.

E3: Desenvolvimento de um novo produto.

E4: Descobrir a necessidade do seu mercado e fazer de uma maneira diferente.

A categoria $\mathbf{C 1}$ também tem relação com tipo e grau de inovação. Evidenciando OCDE (1997), que conceitua inovação de produto como implementação de um bem ou serviço novo ou melhorado. E também com a teoria de Osterwalder, Pigneur e Clark (2011), que conceitua inovação de modelo de negócio como uma valorização que surge das necessidades dos clientes. Sobre grau de inovação, podemos também fazer relação com a OCDE (1997), conceituando inovação incremental como melhoramentos contínuos e radical, desenvolvimento de um novo produto ou serviço.

E1: Depende do tamanho da área, pode ser incremental ou radical.

E2: A gente utiliza as ferramentas que já existem para melhorar o mercado.

E3: Um produto inexistente ainda no mercado.

E4: É descobrir a necessidade do seu mercado e fazer de uma maneira diferente.

A categoria C2: Processo de Pesquisa de Mercado evidencia a etapa de Imersão no Design Thinking para Vianna et al. (2012) é o momento onde são conhecidos os perfis de usuário com foco no ser humano, e com o objetivo de identificar suas necessidades; o autor complementa dizendo que cruzando as informações obtidas será possível identificar insights que serão utilizados na geração de soluções. Segundo Brown (2010) a identificação das necessidades dos usuários ocorre pela empatia e colocando-se no papel desse usuário, além da utilização do pensamento abdutivo.

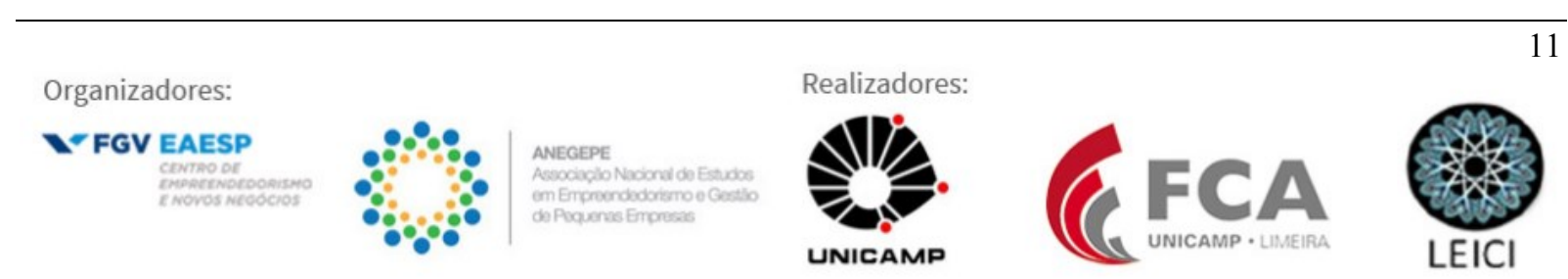


E1: A ideia é ter várias pesquisas para entender como os usuários estão lidando com essas transformações e pegar sugestões de novas ideias e adequações do processo. E2: Se esse mercado ele ia ter uma aceitação do que a gente tá propondo, se os jovens no caso iam ver o valor nesse serviço.

E2: Eu tenho experiência em RH e a partir de ver esse mercado eu também já sabia que tinha esse gap, também foi uma perspectiva minha de mercado.

E2: Negativo da pesquisa de mercado é que a gente não fez de fato aquele tipo ideal pela universidade, a gente optou por fazer um protótipo que ia já testar mais ou menos o que a gente queria.

E3: Descobrir a aceitação do produto.

E3: Ver se tinha alguma parte que determinava mais o produto, se tinha algum sexo, gênero, aquisição financeira.

E4: Pesquisando o mercado para descobrir o que estava precisando.

E4: Foi muito boca a boca, observação e meu estágio.

E4: De forma instintiva.

A categoria C3: Conceito de Design Thinking da Startup representa o conhecimento da teoria e a conceituação da abordagem por parte dos entrevistados; para Signori et al. (2014) o objetivo do Design Thinking é a busca por soluções e atender as necessidades do cliente, favorecendo o desenvolvimento de soluções mais eficientes; E de acordo com Bonini e Endo (2010) afirmam que a abordagem é utilizada para chegar no desenvolvimento de soluções específicas e mais eficazes.

E1: Foco na solução do problema.

E1: Entender a necessidade e viabilizar o projeto.

E1: Fase temporária é boa porque dá para desfazer.

E2: Fazer com que o processo seja mais simples e objetivo, mas que ao mesmo tempo ele tenha todas as informações.

E2: Sempre buscar simplificar tudo para o usuário entender aquilo bem, então sempre pensar no usuário, isso é totalmente Design Thinking.

E3: Forma de raciocinar referente a problemas e soluções.

E4: Eu não conheço.

A categoria C4: Prototipação e Pivotação caracteriza a terceira etapa do Design Thinking no processo de inovação das startups. De acordo com Vianna et al. (2012) prototipações são simulações que antecipam problemas, testam hipóteses e exemplificam ideias trazendo-as à realidade. Conforme MJV (2016) é neste momento que a equipe irá verificar se as ideias são ou não válidas em relação às informações coletadas anteriormente, e lançará aos clientes uma versão simples e funcional do produto.

E2: O site é nosso protótipo, a gente usou ele e vai continuar utilizando, porque é uma forma gratuita.

E2: Ponto forte é que ele abre as portas dentro das empresas.

E2: Ponto fraco do protótipo é que ele não tem todas as funcionalidades que precisa. Então a gente não consegue ainda vender isso para empresa.

E2: Sim, levamos a todos os clientes; levamos até para os investidores, eles veem valor, eles acham que isso é bom porque sabem que estamos testando.

E3: Diversos protótipos, testes com os animais até chegar no resultado final.

E3: O ponto positivo é que depois que chegou no resultado final eu tive $100 \%$ de aceitação dos cachorros.

E3: Ponto negativo da prototipação foi a demora, porque eu demorei mais de um ano para chegar no produto final.

E4: Peça piloto para descobrir os erros.
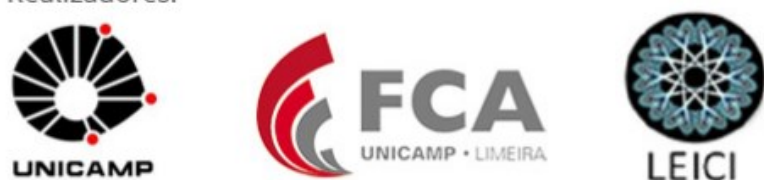
E4: Faço o protótipo no próprio tecido, um tecido às vezes um pouco mais barato, e eu coloco na loja e na maioria das vezes eu vendo esses protótipos.

Ainda na categoria $\mathbf{C 4}$ notou-se que outro conceito foi utilizado nesta etapa de prototipação, o conceito de pivotar. Ries (2012) define pivotar como uma mudança radical no rumo dos negócios, como uma correção de forma estruturada, projetada para testar uma nova hipótese acerca do serviço ou produto.

E2: Através desse site que mandei pra vocês, que é o piloto, a gente conseguiu também fazer uma pesquisa de mercado. Que foi que ajudou a pivotar o projeto.

E3: A ideia inicial não era uma forma líquida, era um pó.

E3: A ideia era utilizar fruta mesmo, quando se tornou líquido a questão de conservação dificultou então foi utilizado apenas a base de aroma.

E4: Depois de dois anos e meio com a loja aberta em Ribeirão Preto percebi que tem que mesclar meu clean com o estilo da cidade, então eu achava que isso era um diferencial, mas na realidade foi um erro de mercado.

A categoria C5: Resultados Obtidos na Combinação da Inovação e Design Thinking está em linha com Macedo, Miguel e Casarotto Filho (2015) e Signori et al. (2014), sobre a adoção do Design Thinking. Segundo Macedo, Miguel e Casarotto Filho (2015) essa abordagem visa a solução de um problema específico com foco no usuário, criando valor para o cliente. Também de acordo com Signori et al. (2014) o Design Thinking tem foco na resolução das necessidades do cliente, seja em produtos ou serviços.

E2: Não foi a partir dessa ferramenta que a startup foi criada, ela só auxilia nos nossos processos.

E4: Para festa eu acabei desenvolvendo a coleção de body e saia, para a pessoa reutilizar o vestido.

E4: Fiz o vestido 2 em 1, longo e curto.

E4: Fiz o body dupla face.

E4: Desenvolvi o "Monte seu vestido de noiva" [...] dessa forma elas se acham a estilista, ela quem está montando o vestido dela, e ela está brincando de Barbie também.

\section{Considerações Finais}

Esta pesquisa foi desenvolvida com o objetivo de responder à seguinte questão de pesquisa: Como as startups utilizam o Design Thinking no seu processo de inovação? Após as entrevistas feitas e analisadas foi possível identificar que todas as quatro startups participantes da pesquisa utilizam ao menos uma etapa presente no conceito de Design Thinking, porém não são todas que possuem o conhecimento amplo de tal abordagem.

Conforme os aspectos apresentados pelos entrevistados, foi identificado que todas as startups apresentam algum tipo e grau de inovação e estão em fase de desenvolvimento e enfrentando incertezas, caracterizando-se assim como uma startup, já que de acordo com Ries (2012) startup é uma instituição desenhada para criar um novo produto ou serviço de forma inovadora e em condições de incerteza.

É possível deduzir que os processos de inovação dessas startups foram positivamente influenciados pelo uso do Design Thinking, e que este uso, na maioria das vezes, ocorreu de forma instintiva sem um conhecimento teórico prévio por parte dos seus proprietários. Foi

Organizadores:
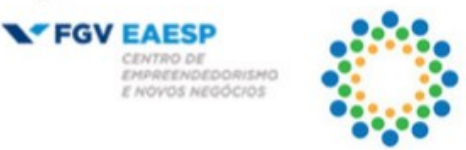

ANEGEPE

Associaglio Nasiond de Estudat

benerentipino
Realizadores:
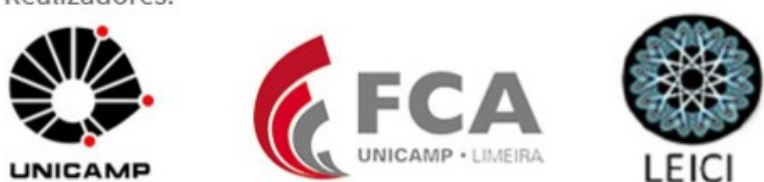
possível detectar que nenhuma das startups estudadas tinha como objetivo inicial a inovação por meio do Design Thinking, mas sim, que o uso da abordagem veio com o decorrer do processo. As startups tiveram como consequência do uso, mesmo que parcial, do Design Thinking, não somente novos produtos, obtiveram também, melhoria e otimização do processo.

É importante ressaltar que a etapa de prototipação foi decisória para a maioria das startups entrevistadas, e que foi recorrente a declaração do uso da pivotação. Tal conceito não foi abordado inicialmente no trabalho, mas pôde-se observar que a pivotação apresentou forte influência nos processos criativos das startups e no desenvolvimento dos seus produtos.

Pelo objetivo geral do trabalho, que foi investigar a utilização da abordagem do Design Thinking no processo de inovação de startups, foi possível perceber que a abordagem ainda não é totalmente conhecida entre as startups, mas é utilizada, mesmo que parcialmente; indo ao encontro com o primeiro objetivo específico de identificar como ocorre a utilização do Design Thinking em startups. A partir das análises entrevistas identificou-se que o uso do Design Thinking ocorre de forma instintiva e pelo pensamento abdutivo, o que está em linha com a teoria de Vianna et al. (2012) e Signori et al. (2014).

O segundo objetivo específico foi verificar as vantagens e desvantagens na utilização do Design Thinking em startups. Para os entrevistados uma das vantagens é ter foco no usuário de forma simples e objetiva, entendendo a necessidade dos potenciais clientes e viabilizando o projeto; outra vantagem apontada é a utilização da prototipação ou fase efêmera, um entrevistado diz ser uma boa etapa já que dá pra ser desfeita; já o segundo entrevistado citou que esta fase abriu portas dentro de empresas; outro diz que após este processo foi alcançado um produto com alto índice de aceitação enquanto outro cita que consegue vender seus protótipos.

Já como desvantagem, o entrevistado E2 relatou que não consegue vender seu protótipo por ainda não ter todas as funcionalidades desejáveis e que ao utilizar tal etapa, não utilizou a etapa de pesquisa de mercado da forma que lhe foi ensinada na universidade. Por sua vez, o entrevistado E3 alegou ter sido um processo demorado.

O terceiro e último objetivo específico foi investigar resultados obtidos por startups ao utilizarem o Design Thinking. Percebeu-se que os três primeiros entrevistados obtiveram maiores resultados nos processos de inovação, enquanto o entrevistado E4 teve maior resultado em produtos obtidos. Vale expor a necessidade da disseminação de matérias ligadas a inovação e empreendedorismo nas universidades, principalmente em cursos que não são voltados para a administração, a fim de preparar e incentivar futuros empreendedores.

A pesquisa teve como limitação a quantidade de startups pesquisadas, logo não é possível estender este estudo de forma generalizada. Contudo, os resultados obtidos podem ser de interesse para a comunidade acadêmica e para startups recém-criadas, ou que estão em fase de concepção. Recomenda-se então, que para pesquisas futuras se utilize um número maior de startups, inclusive startups de outras regiões do país. Vislumbra-se também a possibilidade de se utilizar outras técnicas de análise de dados como o grupo foco ou técnica Delphi. Outra recomendação seria a realização de um estudo voltado para a exploração do conceito de pivotar, também por meio de uma maior quantidade de entrevistas.
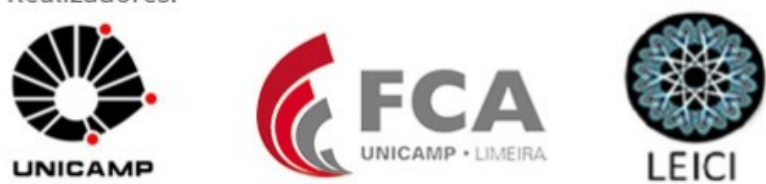


\section{Referências}

ALVES, Fábia Santos. Um estudo das Startups no Brasil. 2013. Monografia (Graduação em Ciências Econômicas). Universidade Federal da Bahia. Salvador.

BARDIN, Laurence. Análise de conteúdo. São Paulo: Edições 70, 2011.

BARROS, Aidil Jesus da Silveira; LEHFELD, Neide Aparecida de Souza. Fundamentos de Metodologia Científica. 3. ed. São Paulo: Pearson Prentice Hall, 2007.

BONINI, Luiz Alberto; ENDO, Gustavo de Boer. Design thinking: uma nova abordagem para inovação. 2010. Disponível em: <http://biblioteca.terraforum.com.br/ Biblioteca Artigo/ artigo-designthinking.pdf $>$. Acesso em: 21 abr. 2017.

BROWN, Tim. Design thinking. Harvard business review, jun. 2008.

BROWN, Tim. Design thinking: uma metodologia poderosa para decretar o fim das velhas ideias. Rio de Janeiro: Elsevier, 2010.

DOLABELA, Fernando. O segredo de Luísa. 2. ed. São Paulo: Cultura, 2006.

DORNELAS, José. Empreendedorismo: transformando ideias em negócios. Rio de Janeiro: Atlas, 2016.

FLICK, Uwe. Uma introdução à pesquisa qualitativa. 2. ed. Porto Alegre: Bookman, 2004.

GIL, Antônio Carlos. Métodos e técnicas de pesquisa social. 6. ed. São Paulo: Atlas, 2008.

HARTMANN, Victor Hugo Pereira. Startup: uma nova forma de aprender. 2013. Monografia (Graduação em Administração). Faculdade de Tecnologia e Ciências Sociais e Aplicadas - FATECS. Brasília.

MACEDO, M.; MIGUEL, P.; CASAROTTO FILHO, N. A Caracterização do Design Thinking como um modelo de inovação. Revista de Administração e Inovação. São Paulo, v. 12, n. 3, p.157-182, jul./set. 2015.

MJV Technology \& Innovation. Update or Die: Como reinventar negócios através do Design Thinking. São Paulo, 2016. Disponível em: $<$ http://cdn2.hubspot.net/hubfs/455690/Ofertas/E-books/Arquivos/EBook-Update-orDie.pdf $>$. Acesso em: 17 mai. 2017.

OCDE. Organização para a Cooperação Econômica e Desenvolvimento. Manual de Oslo: Proposta de Diretrizes para coleta e interpretação de dados sobre inovação tecnológica. 3. ed. Paris: OCDE, 1997.

OSTERWALDER, Alexander; PIGNEUR, Yves; CLARK, T. J. Business model generation: inovação em modelos de negócios: um manual para visionários, inovadores e revolucionários. Rio de Janeiro: Alta Books, 2011.

PORTER, Michael E. Vantagem competitiva: criando e sustentando um desempenho superior. Rio de Janeiro: Elsevier, 1989

RICHARDSON, Roberto Jarry. Pesquisa social: métodos e técnicas. São Paulo: Atlas, 2008. 
RIES, Eric. A startup enxuta: como empreendedores atuais utilizam a inovação contínua para criar empresas extremamente bem-sucedidas. São Paulo: Lua de papel, 2012.

SCHUMPETER, Joseph Alois. Teoria do desenvolvimento econômico: uma investigação sobre lucros, capital, crédito, juro e o ciclo econômico. São Paulo: Abril Cultural, 1982.

SIGNORI, G.; MARTINS, A.; JUNIOR, M.; KALIL, F.; CAPELARI, M. Startup e inovação: inovando na forma de pensar e decretando o fim das velhas ideias. In: XXIV Seminário Nacional de Parques Tecnológicos e Incubadoras de Empresas. Pará - Belém, 2014.

TIDD, Joseph; BESSANT, J. R.; PAVITT, Keith; BECKER, Elizamari Rodrigues (Trad.). Gestão da inovação. 5. ed. Porto Alegre: Bookman, 2015. 633 p. ISBN 9788582603062 .

VARRICHIO, Pollyana Carvalho. Uma discussão sobre a estratégia de inovação aberta em grandes empresas e os programas de relacionamento voltados para Startups no Brasil. RACEF - Revista de Administração, Contabilidade e Economia da Fundace. v. 7, n. 1, Ed. Esp. Ecossistemas de Inovação e Empreendedorismo, p. 148-161, 2016.

VIANNA, M.; VIANNA, Y.; ADLER, I. K.; LUCENA, B.; RUSSO, B. Design thinking: inovação em negócios. Rio de Janeiro: MJV Press. Disponível em $<$ http://www.sebraedesign.com/wp-content/uploads/2013/05/Design-ThinkingInova\%C3\%A7\%C3\%A3o-em-Neg\%C3\%B3cios.pdf > . Acesso em setembro, 2017.

ZAWISLAK, Paulo Antônio. A Relação entre Conhecimento e Desenvolvimento: Essência do Progresso Técnico. Revista Análise: PUC. Porto Alegre, 2008. 